\title{
Epiderme em cena: raça, nação e teatro negro no Brasil
}

\author{
Luiz Gustavo Freitas Rossi**
}

\begin{abstract}
Pode-se dizer que os estudos dos mecanismos do maquinário social, através do qual certos símbolos se "universalizam" e passam a elaborar códigos supostamente expressivos de identidades e culturas nacionais, se valeram, em grande medida, da mobilização de materiais provenientes dos mais diversos gêneros da produção cultural. No Brasil, em particular, não seria arriscado afirmar que a literatura $e$ o pensamento social ofereceram um dos pontos de apoio privilegiados para apreender as representações "do nacional". $\mathrm{Na}$ análise exaustiva da história literária e intelectual, importantes trabalhos devassaram os anos de 1920 e 30, entendidos como os momentos catalisadores para a construção e projeção de uma identidade nacional mestiça e, em particular, devedora aos elementos culturais reconhecidos como "negros". Entretanto, neste período em que símbolos - tais como a malandragem, o samba e a mulata - passaram a aglutinar sentidos renovados de brasilidade, intelectuais, cientistas e literatos não foram os únicos a desempenharem um papel vigoroso na manipulação e divulgação destes símbolos.
\end{abstract}

\footnotetext{
" Recebida para publicação em novembro de 2006. Resenha dos livros de Orlando de Barros, Corações de Chocolat: a história da Companhia Negra de Revistas (1926-27) (2005) e de Tiago de Melo Gomes, Um Espelho no Palco: identidades sociais e massificação da cultura no teatro de revista dos anos de 1920 (2004).

** Doutorando em Antropologia Social no Instituto de Filosofia e Ciências Humanas da Universidade Estadual de Campinas (Bolsista Fapesp). lgusfrossi@hotmail.com
} 
Raça, nação e teatro negro no Brasil

Como mostram com bastante competência os livros dos historiadores Orlando de Barros, Corações de Chocolat, e Tiago de Melo Gomes, Um Espelho no Palco, no Rio de Janeiro, em meados da década de 1920, não era preciso ficar antenado na produção intelectual para se perceber que novas maneiras de representar o Brasil estavam sendo formuladas. Para tanto, bastava estar em contato com as oportunidades de entretenimento oferecidas à época, na então capital federal. No manejo minucioso de farta e ampla documentação, Barros e Gomes se lançam na recuperação do circuito de divertimentos cariocas, no período Pós-Primeira Guerra - com seus cabarés, cafés-cantantes, cinemas e teatros -, numa chave de leitura que enfatiza as inscrições destes espaços na produção e veiculação, a um público amplo $e$ segmentado, de imagens de um Rio de Janeiro e um Brasil "mestiços".

Desse modo, não surpreende a proximidade entre Corações de Chocolat e Um Espelho no Palco, principalmente, no que diz respeito aos eixos de sustentação de suas análises. De um lado, remontam as engrenagens de funcionamento daquilo que foi um dos entretenimentos mais populares do período: o teatro de revista, gênero teatral musicado e "leve", estruturado essencialmente pela encenação cômica das "novidades" $e$ acontecimentos sociais e políticos do momento. De outro, esquadrinham as implicações sociais e ideológicas mais amplas condicionadas pela atuação de uma companhia teatral em particular: a Companhia Negra de Revistas.

Corações de Chocolat, de Orlando de Barros, é um trabalho impecável de reconstrução do itinerário da Companhia Negra de Revistas, em seu processo de formação, ascensão e declínio, entre os anos de 1926 e 1927. Embora curta, a existência desta companhia exaltou os ânimos da cena do entretenimento carioca, levando aos palcos não apenas uma trupe composta quase inteiramente por artistas negros e mulatos, mas também espetáculos nos quais as referências à epiderme e à cultura afrobrasileira foram uma constante. Afinal, mesmo não sendo uma 
novidade, pois não havia muitos obstáculos ao fato de que "músicos negros tocassem nas orquestras dos teatros, ocultos no fosso, ou à parte, sem destaque nem foco de luzes" (13), levar ao centro dos palcos um empreendimento artístico coletivamente concebido nos termos de um "teatro negro" não deixou de provocar comentários e constrangimentos de várias ordens.

Idealizado por João Cândido Ferreira (1887-1956) - ele próprio um artista mulato $e$, nesse sentido, conhecido no mercado revisteiro por "De Chocolat" -, a companhia teve como referências mais imediatas modelos cênicos do teatro norteamericano que, com o final da primeira guerra, nos últimos anos da década de 1910, lograram grande êxito na Europa e, em particular, na França. Espetáculos envolvendo artistas afroamericanos atingiram em cheio o gosto do público parisiense, ao mobilizar elementos bastante arraigados no imaginário colonial francês traduzidos nos palcos em performances que estilizavam uma África primitiva e exótica e, como não dizer, erótica. A Revue Nègre, um desses empreendimentos mais bem sucedidos, realizado em 1925, consagrou o "negrismo" como a "grande moda" do momento com suas peças ágeis, suas danças "selvagens", embaladas pelo ritmo "frenético" do jazz, e a energia "bárbara" dos rodopios e requebros "sensuais" das black girls. Uma das mais famosas, Josephine Baker, conquistou notoriedade internacional apresentando-se na Revue Nègre com seus vestuários "primitivos" de tanga de penas e frutas como adereços, lembrando em tudo, como chama a atenção Orlando de Barros, o estilo "negro" com o qual se consagrou mais tarde Carmen Miranda. Sempre de olho em Paris, não demorou muito para que a elite e a imprensa cariocas criassem certas expectativas de que algo semelhante surgisse no Brasil. Contudo, se o negro e o africano podiam ser percebidos pelos franceses num registro distanciado, como elementos seguramente estrangeiros à sua vida social e cultural, no Brasil, a presença mais ampla da "gente de cor" nos espetáculos ganhava nuanças particulares. Em boa medida, significava aceitar $e$ incorporar como elementos de 
Raça, nação e teatro negro no Brasil

destaque no entretenimento um segmento de sua população que há tempos era percebido como um dos principais entraves ao progresso e à modernização da nação.

Assim, Corações de Chocolat não trata apenas da história singular de uma companhia teatral. À medida que vai articulando os episódios "miúdos" da Companhia Negra de Revistas, Orlando de Barros revela a significação mais ampla de seu objeto, não só para a compreensão das convenções do teatro de revista, mas também para o entendimento adensado dos sentidos práticos $e$ cotidianos atribuídos à "raça negra" e às relações raciais brasileiras nos anos de 1920. Num momento em que discursos preconceituosos e idéias de inferioridade racial circulavam livremente, os debates críticos que se seguiram às encenações das peças de De Chocolat (Tudo Preto, Café Torrado, Carvão Nacional, entre outras) foram representativos dos "desarranjos" que essas revistas negras causaram no sistema de valores da elite carioca, ao ver suas fantasias de branquitude serem minadas. $\mathrm{O}$ reconhecimento dessas revistas negras, embora logrados pelos seus aspectos técnicos - marcações bem feitas, cenários luxuosos, músicas ágeis e dançantes -, não conseguiu fugir ao expediente da cor como seu principal eixo controlador. Paradoxalmente, "a cor" funcionou como um marcador que, ao mesmo tempo, valorizava e depreciava os empreendimentos da Companhia Negra de Revistas. Os juízos favoráveis à companhia, no limite, acabavam se convertendo em móvel de ideologias racialistas, através das quais se formulavam argumentos de toda espécie sobre as limitações biológicas e culturais e os "devidos lugares" do negro na sociedade brasileira. Enquanto em "Paris exibiram-se pretos artistas; aqui se exibiam os nossos copeiros $e$ as nossas cozinheiras... havia uma pequena diferença" (105).

Embora nada elogiosa, e talvez a contragosto, a crítica recolhida pelo autor acertava um alvo preciso: o Brasil estava longe de ser a França. Por aqui, a importação do teatro negro ainda que trouxesse o carimbo de qualidade dos "ultracivilizados" franceses - forçou de maneira incômoda um debate sobre as 
próprias representações da nação. No confronto entre aquilo que se percebia como "nosso" e "estrangeiro" nas peças da companhia, Orlando de Barros mostra como os críticos passaram a enfatizar os momentos "bem brasileiros" das peças. Na música, em meio aos ritmos internacionais variantes do jazz, como o onestep e o charleston, a atenção recaiu sobre o "brasileiríssimo" Pixinguinha que, com sua "flauta mágica", encantou as platéias executando seus choros, sambas e maxixes. Nos palcos, o colorido todo nacional estava garantido pela figura estilizada da "baiana" ou mesmo pelo quadro Mãe Preta, o último da revista Tudo Preto, apreendida como a representação sintética da "ama de leite", cujos seios alimentaram os rebentos da elite patriarcal brasileira. O ápice dessa discussão se deu quando, em meados de 1927, após acumular seguidos sucessos por outros estados (São Paulo, Bahia, Pernambuco e Rio Grande do Sul), surgiram rumores de uma possível apresentação da Companhia Negra, em Buenos Aires. Foi neste momento que se revelou toda a fragilidade dos trunfos conquistados pela trupe.

Apropriado para a diversão e o consumo interno, mas condenado como produto de exportação, o país enegrecido da companhia foi entendido como um "atentado aos foros de nossa civilização" (230). Talvez, com um pouco de exagero, Orlando de Barros acredite que "houve uma verdadeira conspiração contra a trupe negra" (232). Isto porque, com os rumores da excursão ao estrangeiro, iniciou-se uma campanha, envolvendo inclusive os poderes públicos e o próprio Ministério das Relações Exteriores, no sentido de impedir tal "propaganda" do país. De certo modo, já frágil por uma série de conflitos internos, o episódio foi decisivo para a dissolução da Companhia Negra de Revistas. Contudo, ainda que impedida de mostrar aos argentinos um país negro, as peças da companhia já apontavam para o esgotamento social, cultural e político das apostas num projeto de Brasil branco. Mesmo desprezados e considerados cidadãos de segunda classe, os afro-brasileiros não podiam mais ser ignorados como elementos formadores da sociedade, da cultura e da "civilização" brasileiras. 
Raça, nação e teatro negro no Brasil

Portanto, estava nítido que a incorporação de símbolos negros na produção de um repertório sobre a nacionalidade começou a borrar a máscara branca - para inglês ver - do Brasil. $\mathrm{O}$ mundo do entretenimento acabou por se transformar num eficaz espelho, com o qual o país se enxergava. Não por acaso, esta é a idéia que encerra o título do livro de Tiago de Melo Gomes: Um Espelho no Palco. Contudo, enquanto Corações de Chocolat empreende uma análise "microscópica" da Companhia Negra, Um Espelho no Palco toma a trupe de De Chocolat como um material de potencial heurístico mais amplo, estabelecendo um confronto sistemático com outras revistas do período. De maneira articulada, Tiago de Melo Gomes mostra com desenvoltura como raça, classe e gênero funcionaram como marcadores sociais expressivos, nos palcos do entretenimento carioca, para estruturação de linguagens, performances $e$ categorias de percepção da modernidade na década de 1920. Revestindo de comicidade e graça os temas palpitantes ou controversos do momento, o teatro de revista converteu-se num reservatório farto de impressões sobre uma série de mudanças na vida cotidiana, essencialmente entendidas como decorrentes dos "novos" hábitos e estilos de vida modernos. Como destaca Gomes, uma questão central nas peças do período era "a reestruturação de identidades tendo como pano de fundo a velocidade da vida moderna" (204). O automóvel inundando a paisagem urbana, os banhos de mar, as novas danças que permitiam uma maior "liberdade do corpo", a moda dos cabelos curtos para mulheres (ou à la garçonne), a percepção de uma maior presença feminina no espaço público, bem como suas iniciativas mais ousadas nos flertes e nas relações amorosas, todos esses elementos foram referências recorrentes na diagramação dos enredos e quadros teatrais.

Trazendo em seu socorro um número variado de fontes (memórias, recepções críticas e o próprio conteúdo substantivo das peças), Gomes desvela os efeitos perturbadores que os novos comportamentos exerceram nas mentalidades de certos grupos 
sociais. Cronistas e membros da elite não deixaram de expressar sua preocupação com a perda do "recato" e do "decoro" das senhoritas da alta sociedade que, expostas aos valores da modernidade, estavam à beira da ruína moral. A "melindrosa", personagem comum do teatro de revista da época, buscava tipificar a afetação das jovens "chiques", afeitas às aventuras amorosas e às performances corporais que sugeriam certa disponibilidade sexual, aproximando-as perigosamente dos padrões de valores e posturas freqüentemente associados às prostitutas, mas principalmente, à figura da "mulata". $\mathrm{O}$ "cruzamento entre gênero, raça e sexualidade" foi central para a "estruturação de algumas percepções mais refratárias à modernidade" (264). Uma modernidade que, como faz questão de enfatizar Gomes, aparecia enegrecida. Contudo, se, de um lado, a "civilização" parecia encaminhar "jovens senhoritas" a adotarem posturas sexualmente condenáveis, semelhantes àquelas que modulavam o imaginário social em torno da "mulata", de outro, a presença do elemento de "classe", articulada à raça, acabava por funcionar como contraponto aos efeitos tidos como perturbadores da modernidade. Antítese do "artificialismo" das melindrosas $e$ dos almofadinhas, os personagens representados como pobres $e$ negros no teatro de revista ganhavam relevo por suas características "desafetadas", o jeito honesto de ganhar a vida $e$ "recatada" no plano moral. Nesse sentido, essa é uma das hipóteses aventada por Um Espelho no Palco para explicar que

\begin{abstract}
a associação de tipos afro-brasileiros com a nacionalidade tenha sido o desejo de espelhar a nação em termos antimodernos (...) de modo a se contrapor às novidades vistas como desagradáveis que desfilavam nos ambientes chiques da capital federal diariamente (267).
\end{abstract}

Em grande medida, portanto, Tiago de Melo Gomes enxerga na Companhia Negra de Revistas o empreendimento teatral que, quando surgiu em 1926, melhor explorou e sintetizou 
Raça, nação e teatro negro no Brasil

a relação entre a questão racial $e$ a nacionalidade brasileira. As peças da companhia não apenas reivindicavam um orgulho racial - afinal, como dizia um personagem de Tudo Preto: "o preto é que est[ava] na moda" -, mas também defendiam a idéia de um Brasil "mestiço", onde era possível a boa convivência racial. Sem dúvida, Gomes traz subsídios novos ao tema da representação "mestiça" da nacionalidade brasileira, repensando a "tese de que a idéia foi criada por intelectuais e políticos, seja ou não para fins de dominação" (324). Muito pelo contrário, tratava-se de idéias e conceitos negociados quase que diariamente no "polissêmico" mundo do entretenimento. Apenas é de se lamentar, em Um Espelho no Palco, uma ausência que, presente em Corações de Chocolat, daria um outro potencial à análise: elementos visuais. As fotos e charges que deram conta da trajetória da Companhia Negra, veiculadas nos jornais da época, sintetizaram de modo singular os sentimentos ambíguos despertados por suas peças.

Ora, como mostram Corações de Chocolat e Um Espelho no Palco, as representações de um Brasil enegrecido apareciam como uma daquelas imagens tão desconcertantes e escandalosas que apenas conseguiam ser evocadas como paródia ou caricatura chistosa da realidade social. Revestida pelo riso, objetivo máximo do teatro de revista, a Companhia Negra foi capaz de chamar a atenção para um Brasil que, talvez, não seria bem recebido ou levado a sério se afirmado, ou melhor, "visto" de outra forma ou em outros contextos. 